\title{
Assessment of testicular steroidogenic enzymes expression in experimental animal model following withdrawal of nandrolone decanoate
}

\author{
TaeSun Min ${ }^{1}$, Adhimoolam Karthikeyan ${ }^{2}$ and Ki-Ho Lee $^{3 *}$ \\ ${ }^{1}$ Department of Animal Biotechnology, Jeju National University, Jeju 63243, Korea \\ ${ }^{2}$ Subtropical Horticulture Research Institute, Jeju National University, Jeju 63243, Korea \\ ${ }^{3}$ Department of Biochemistry and Molecular Biology, College of Medicine, Eulji University, Daejeon \\ 34824, Korea
}

Received: Jul 18, 2021

Revised: Aug 24, 2021

Accepted: Sep 1, 2021

${ }^{*}$ Corresponding author

Ki-Ho Lee

Department of Biochemistry and

Molecular Biology, College of Medicine,

Eulji University, Daejeon 34824, Korea.

Tel: +82-42-259-1643

E-mail: kiholee@eulji.ac.kr

Copyright () 2021 Korean Society of Animal Sciences and Technology. This is an Open Access article distributed under the terms of the Creative Commons Attribution Non-Commercial License (http:// creativecommons.org/licenses/by$\mathrm{nc} / 4.0 /$ ) which permits unrestricted non-commercial use, distribution, and reproduction in any medium, provided the original work is properly cited.

ORCID

TaeSun Min

https://orcid.org/0000-0002-3998-7493

Adhimoolam Karthikeyan

https://orcid.org/0000-0002-6270-5597

Ki-Ho Lee

https://orcid.org/0000-0002-3495-5126

Competing interests

No potential conflict of interest relevant to this article was reported.

Funding sources

This research was supported by the 2021 scientific promotion program funded by Jeju National University.

Acknowledgements

Not applicable.

\section{Abstract}

Anabolic steroids are frequently used to increase the growth rate of meat-producing animals. Exposure to an anabolic-androgenic steroid, nandrolone decanoate (ND), is associated with expressional reduction of testicular steroidogenic enzymes. However, the effect of withdrawal of ND exposure on the expression of these testicular molecules has not been thoroughly explored. The current research investigated expression changes of testicular steroidogenic enzymes in rats at several recovery periods $(2,6$, and 12 weeks) after the stop of ND treatment with different doses (2 and $10 \mathrm{mg} / \mathrm{kg}$ body weight) for 12 weeks. Body and testis weights were recorded, and transcript levels of molecules were determined by quantitative real-time polymerase chain reaction (PCR). The immunohistochemistry was used to examine the changes of immuno-intensities of molecules. At 6 and 12 weeks of the recovery period, the $10 \mathrm{mg} / \mathrm{kg} \mathrm{ND-treated} \mathrm{rats} \mathrm{were} \mathrm{lighter} \mathrm{than} \mathrm{other} \mathrm{ex-}$ perimental groups. The interstitial compartment vanished by ND treatment filled up as the recovery period became longer. The expression of steroidogenic acute regulatory protein was returned to the control level at 12 weeks of the recovery period. Expression levels of cytochrome P450 sidechain cleavage and 17a-hydroxylase were increased in $2 \mathrm{mg} / \mathrm{kg} \mathrm{ND}$-treated group at 6 weeks of the recovery period, and transcript levels of these molecules in 2 and $10 \mathrm{mg} / \mathrm{kg} \mathrm{ND-treated} \mathrm{groups}$ at 12 weeks of the recovery period were significantly lower than the control. Expression levels of $3 \beta$-hydroxysteroid dehydrogenase (HSD) type I and 17ß-HSD type 3 in $2 \mathrm{mg} / \mathrm{kg}$ ND-treated group were comparable with those of control at 12 weeks of the recovery period, but not in $10 \mathrm{mg} / \mathrm{kg}$ ND-treated group. Expression of cytochrome P450 aromatase (Cyp19) was reverted to the control level at 2 weeks of the recovery period. Except for Cyp19, there was a visible increase of immuno-staining intensity of other testicular steroidogenic enzymes in the Leydig cells as the recovery period progressed. This research has demonstrated that the cease of ND administration could restore the expression of testicular steroidogenic enzymes close to the normal level. Nevertheless, a relatively long recovery period, compared to the ND-exposure period would be required to retrieve normal expression levels of testicular steroidogenic enzymes.

Keywords: Testis, Steroidogenic enzymes, Leydig cell, Gene expression, Nandrolone decanoate, Recovery period 
Availability of data and material Not applicable.

Authors' contributions

Conceptualization: Min T, Lee KH.

Data curation: Lee KH.

Formal analysis: Min T.

Methodology: Min T.

Software: Lee KH.

Validation: Lee $\mathrm{KH}$.

Investigation: Lee $\mathrm{KH}$.

Writing - original draft: Lee KH

Writing - review \& editing: Min T, Karthikeyan $\mathrm{A}$, Lee $\mathrm{KH}$.

Ethics approval and consent to participate The present study was carried out in accordance with the guide for the care and use of laboratory animals of the National Research Council in Korea and it was approved by the Ethics Committee for Animal Use, Eulji University (EUIACUC 20-04).

\section{INTRODUCTION}

Anabolic steroids are used to increase the growth rate of meat-producing animals, such as cattle, sheep, and pigs after severe scrutiny and testing. It is also taken by athletes to gain muscle and improve strength. Out of naturally existing anabolic-androgenic steroid (AAS) compounds, nandrolone (19-nortestosterone) has a more powerful anabolic effect than testosterone [1] and is detectable in boar serum and meat at an unneglectable level [2,3]. Esterified form at $\mathrm{C} 17$ position of nandrolone, commercially named nandrolone decanoate (ND), is also chemically synthesized and used for medical purposes to treat muscle wasting, accompanied with human immunodeficiency virus (HIV) infection, and anemia associated with chronic renal failure [4]. However, unregulated and non-clinical use of ND for improving athletic performance and muscle mass is frequently connected with various adverse effects, including endocrinological, cardiovascular, and psychiatric effects [5]. Moreover, a strong association between men's infertility and the abuse of ND has been reported in previous studies $[5,6]$.

Male fertility is regulated by various intrinsic and/or extrinsic factors, and adequate production of testosterone from the testis is important for maintaining the normal function of the male reproductive system [7]. The testicular testosterone is chiefly synthesized in the Leydig cells within the interstitial compartment of the testis [8]. The sequential reaction of several steroidogenic enzymes, including steroidogenic acute regulatory protein (Star), cytochrome P450 side-chain cleavage (Cyp11a1), 3 $\beta$-hydroxysteroid dehydrogenase (Hsd3b), cytochrome P450 17 $\alpha$-hydroxylase (Cyp17), and 17 $\beta$-hydroxysteroid dehydrogenase $(H s d 17 b)$, converts cholesterol into testosterone within the Leydig cell [8]. An additional action of cytochrome $\mathrm{P} 450$ aromatase $\left(C_{y p} 19\right)$ is necessary to aromatize testosterone into estradiol [8]. All of these testicular steroidogenic enzymes are localized in the Leydig cell, and CYP19 is also present in the Sertoli cell and some types of germ cells $[8,9]$. Thus, structural disruption of the interstitial compartment in the testis could influence the expression of steroidogenic enzymes and the production of testosterone and estrogen from the testis.

The depletion of the interstitial composition and the sloughing of germinal cells within the seminiferous tubules are commonly observed with exposure to ND $[10,11]$. Such structural disturbance of the rat testis is more severe with a higher dose and a longer period of the ND treatment [12]. A decreased expression of testicular steroidogenic enzymes by ND administration is associated with the severity of depletion of the interstitial compartment, that is, lesser interstitial constituent, the more reduced expression level of steroidogenic enzymes in the ND-treated testis [12]. In fact, previous research has shown that expression of most steroidogenic enzymes declines with a low-dose (2 mg/kg body weight [BW]) ND administration for 12 weeks and a high-dose $(10 \mathrm{mg} / \mathrm{kg} \mathrm{BW}) \mathrm{ND}$ administration for 2 or 12 weeks, except for Cyp11a1, which shows a rapid decrease in the expression level at a low-dose ND treatment just for 2 weeks [12]. Other research groups have reported an altered expression of testicular steroidogenic enzymes by ND treatment $[13,14]$. Together, these findings demonstrate that the destructive effects of ND treatment in the testis result in a decline of testosterone production from the testis and a drop in serum testosterone concentration [11,12].

The cytotoxic and histopathological damages induced by ND administration are found not only in the reproductive system but also in other organs and tissues, including the heart and kidney [15]. Due to such undesirable consequences of ND administration, prolonged use of ND is not common. Many studies have shown the withdrawal effect of ND usage in various tissues, and some have shown that histopathological alterations in the kidney and changes of certain serum lipid profiling induced by ND administration are reversible after its withdrawal [16,17]. However, 
others have demonstrated that the deleterious effects of ND usage on the histological structure of the heart, kidney, and testis are not completely reversible [15]. Additionally, the harmful impacts of ND on the female reproductive system, including estral acyclicity [18], histopathological changes in ovary, uterus, and fallopian tube [18-20], and aberrant expression of androgen receptor and estrogen receptors $\alpha$ and $\beta$ [19] in the fallopian tube, are not completely restored within certain recovery periods. Despite contradictions regarding the reversibility of ND-induced harmful outcomes followed by the withdrawal of ND administration, it has not been examined whether the cease of ND usage could reverse aberrant expression of testicular steroidogenic enzymes caused by the exposure to ND.

Thus, the present research has been designed to determine expression changes of testicular steroidogenic enzymes at three different recovery periods (2, 6, and 12 weeks) after ND treatment at 2 or $10 \mathrm{mg} / \mathrm{kg}$ BW for 12 weeks. Additionally, the restoration of abnormal histology observed in ND-treated testis has been evaluated by microscopic investigation.

\section{MATERIALS AND METHODS}

Experimental animals, nandrolone decanoate treatment, and the recovery after the withdrawal of treatment

Male Sprague Dawley rats of 40 days of age, purchased from Samtako (Osan, Korea), were used for the current study. Rats were individually caged with free access to food and drinking water under a controlled environment during the experimental period. The treatment of ND was performed as described in the previous research [12]. Briefly, the ND (Deca-Durabolinâ) obtained from Organon Korea (Seoul, Korea) was diluted to make working solutions with peanut oil. The animals of 50 days of age were randomly divided into three treatment groups, control (peanut oil), $2 \mathrm{mg}$ of ND/kg $\mathrm{BW} /$ week, or $10 \mathrm{mg}$ of ND/kg BW/week treatment. Each treatment group was divided into three subgroups according to the recovery period, 2, 6, and 12 weeks, and each subgroup consisted of 5 to 6 rats. All experimental animals were subcutaneously treated with ND for 12 weeks, and body weight was recorded weekly. The present study was carried out in accordance with the guide for the care and use of laboratory animals of the National Research Council in Korea, and it was approved by the Ethics Committee for Animal Use, Eulji University (EUIACUC 20-04).

After the last ND injection in the 12th week, animals were given 2, 6, or 12 weeks of the recovery period. At the end of each recovery period, body weight was measured, and animals were anesthetized by $\mathrm{CO}_{2}$ stunning. The male reproductive tract was isolated, and the testis was quickly separated from the remaining part in cold PBS and weighted. The fixation of testis was achieved by Bouin's solution for immunohistochemical analysis, and the other testis was rapidly minced into small pieces before freezing in liquid nitrogen. The frozen testicular tissues were kept at $-80^{\circ} \mathrm{C}$ and used for real-time polymerase chain reaction (PCR) analysis.

RNA isolation, cDNA synthesis, and real-time polymerase chain reaction analysis Total RNA from the testis was isolated using TRIzol reagent (Molecular Research Center, Cincinnati, OH, USA). Homogenized $50 \mathrm{mg}$ of testis tissue in $1 \mathrm{~mL}$ of RNA extraction solution was centrifuged at $16,609 \times \mathrm{g}$ for $20 \mathrm{~min}$, and the total RNA was extracted and precipitated by the addition of chloroform and isopropanol. The total RNA was dissolved in RNA storage solution (Ambion, Austin, TX, USA) and stored at $-80^{\circ} \mathrm{C}$ before constructing the first-stranded cDNA. The concentration of the total RNA was estimated by UV spectrophotometer (Eppendorf, New York, NY, USA), and $1.2 \%$ agarose gel electrophoresis was employed to check the quality of the total RNA. 
One mg of the total RNA was used to construct the first-stranded cDNA by using iScrip ${ }^{\text {TM }}$ Reverse transcription Supermix for reverse transcription (RT)-qPCR (Bio-Rad Laboratories, Hercules, CA, USA). The RT reaction was performed at $25^{\circ} \mathrm{C}$ for $5 \mathrm{~min}, 46^{\circ} \mathrm{C}$ for $20 \mathrm{~min}$, and $95^{\circ} \mathrm{C}$ for $1 \mathrm{~min}$ in a sequential manner. The quantitative real-time PCR analysis was carried out in 1 $\mu \mathrm{L}$ of generated cDNA, $7 \mu \mathrm{L}$ of iQTM SYBR ${ }^{\circledR}$ Green Supermix (Bio-Rad Laboratories, Hercules, CA, USA), 10 pmol of a primer set, and nuclease-free $\mathrm{dH}_{2} \mathrm{O}$ to make a reaction volume of 25 $\mu \mathrm{L}$. The Primer 3 software (https://bioinfo.ut.ee/primer3) was used to design the oligonucleotide primers for real-time PCR analysis, and detailed information for primers is shown in Table 1 . The molecules examined in this research were Star, Cyp11a1, Cyp17, 3 $\beta$-hydroxysteroid dehydrogenase/ delta-5-delta-4-isomerase type I (Hsd3b1), 17 $\beta$-hydroxysteroid dehydrogenase 3 (Hsd17b3), and Cyp19. The PCR condition was as follows: a pre-denaturation step at $95^{\circ} \mathrm{C}$ for $5 \mathrm{~min}$, cycles of a denaturation step at $95^{\circ} \mathrm{C}$ for $30 \mathrm{~s}$, an annealing step at $\mathrm{T}_{\mathrm{m}}$ for $30 \mathrm{sec}$, and an extension step at $72^{\circ} \mathrm{C}$ for $30 \mathrm{~s}$, and an extra extension step at $72^{\circ} \mathrm{C}$ for $10 \mathrm{~min}$. The PCR was performed in PTC200 Chromo 4 real-time system (BioRad Laboratories), and the size of the PCR product was confirmed by $1.2 \%$ agarose gel electrophoresis. Cyclophilin A (Ppia) was included as an internal PCR control.

\section{Hematoxyling and eosin and immunohistochemical staining}

The fixed testis in Bouin's solution overnight was transferred to 70\% $\mathrm{EtOH}$ and dehydrated in a series of $90 \%, 95 \%$, and $100 \% \mathrm{EtOH}$. Then, the testis was cleared in xylene and infiltrated and embedded with paraffin. The testis paraffin block was cut into $4 \mathrm{~mm}$ thickness for further Hematoxyling and Eosin (H\&E) and immunohistochemical staining.

The testis section for $\mathrm{H} \& \mathrm{E}$ staining was deparaffinized in xylene and rehydrated in a series of 95\%, 90\%, and 70\% $\mathrm{EtOH}$ and running water. The section was then stained with hematoxylin (YD Diagnostics, Yongin, Korea) for $1 \mathrm{~min}$ at room temperature, followed by washing through running water. After immersion in eosin solution (Millipore, Burlington, MA, USA) for 1 min, the section was directly dehydrated in a series of ethanol and cleared with xylene. Finally, it was mounted and placed under light microscopy for histological examination.

For immunohistochemical staining, a deparaffinized and rehydrated section was microwaved in $0.01 \mathrm{M}$ citrate buffer $(\mathrm{pH} 6.0)$ for $10 \mathrm{~min}$ for antigen retrieval. Inactivation of endogenous peroxidase was performed in $0.3 \% \mathrm{H}_{2} \mathrm{O}_{2} /$ methanol for $15 \mathrm{~min}$, and nonspecific binding of the primary antibody was blocked by incubation with $5 \%$ normal goat serum (Millipore) for $30 \mathrm{~min}$ at room temperature. Then, the section was treated with the primary antibody in a humidified chamber at $4^{\circ} \mathrm{C}$ overnight. The preliminary trials were made to select proper concentrations of

Table 1. Primers used for quantitative real-time PCR analysis

\begin{tabular}{lllcc}
\hline \multicolumn{1}{c}{ Gene (GenBank ID) } & \multicolumn{1}{c}{ Forward primer sequence } & \multicolumn{1}{c}{ Reverse primer sequence } & T $\left.\mathbf{T}_{\mathbf{m}}{ }^{\circ} \mathrm{C}\right)$ & Expected PCR size $(\mathbf{b p s})$ \\
\hline Star (NM_031558) & CTGCTAGACCAGCCCATGGAC & TGATTTCCTTGACATTTGGGTTCC & 66 & 91 \\
Cyp11a1 (J05156) & AGGTGTAGCTCAGGACTT & AGGAGGCTATAAAGGACACC & 52 & 399 \\
Cyp17 (M31681) & AGATTGACCAGTACGTAGGCTTCAGCCGAA & CACATCCAAGTCAAACCTCTGCAGTAGC & 67 & 410 \\
Hsd3b1 (M38178) & CCCATACAGCAAAAGGATGG & GCCGCAAGTATCATGACAGA & 55 & 150 \\
Hsd17b3 (NM_054007.1) & CTCCCAACCTGCTCCCAAGTCATTT & AGCAAGGCAGCCACAGGTTTCAGC & 65 & 408 \\
Cyp19 (M33986) & GCTTCTCATCGCAGAGTATCCGG & CAAGGGTAAATTCATTGGGCTTGG & 62 & 290 \\
Ppia (NM_017101) & GGCAAATGCTGGACCAAACAC & TTAGAGTTGTCCACAGTCGGAGATG & 62 & 196 \\
\hline
\end{tabular}

PCR, polymerase chain reaction; PCR, polymerase chain reaction; Star, steroidogenic acute regulatory protein; Cyp11a1, cytochrome P450 side chain cleavage; Cyp17, cytochrome P450 17a-hydroxylase; Hsd3b1, 3ß-hydroxysteroid dehydrogenase/delta-5-delta-4 isomerase type I; Hsd17b3, 17ß-hydroxysteroid dehydrogenase 3; Cyp19, cytochrome P450 aromatase; and Ppia: cyclophilin A. 
primary antibodies for immunohistochemical analysis. The present study used dilutions of 1:150 for StAR (orb7014; Biobyt, Cambridge, UK), 1:1,000 for CYP11A1 (ABS235, Millipore), 1:200 for CYP17 (bs-3853R, Bioss, Woburn, MA, USA), 1:400 for HSD3B1 (orb5478, Biobyt), 1:400 for HSD17B3 (orb5476, Biobyt), and 1:100 for CYP19 (bs-0114R, Bioss). After washing in PBS, the section was incubated with biotinylated goat anti-rabbit IgG secondary antibody (DAKO, Glostrup, Hovedstaden, Denmark) of 1:100 dilution for $1 \mathrm{~h}$ and then with elite avidin-biotinperoxidase (Vector Laboratories, Burlingame, CA, USA) for $30 \mathrm{~min}$ at room temperature. The positive immuno-staining on the section was detected with a mixture of 3,3'-diaminobenzidine (Sigma, St. Louis, MO, USA), 0.05 M Tris-HCl buffer, and 5\% hydrogen peroxide. The section counterstained with hematoxylin was mounted, and the immuno-reactivity of the section was evaluated under light microscopy. For negative control, normal rabbit serum (Millipore) was applied to tissue sections at the same dilutions in the place of primary antibodies. Digitalized images of H\&E and immunohistochemistry staining were captured with Olympus-CoolSNAP cf color/OL camera (Olympus America, Melville, NY, USA), using RSImage version 1.1 software (Roper Scientific, Acton, MA, USA). The process of these digital images was carried out in Adobe PhotoShop CS5 software (Adobe Systems, San Jose, CA, USA).

\section{Statistical analysis and data presentation}

We have carried out a real-time PCR analysis of the triplicated RT reaction and real-time PCR for each sample. The mean value of each target molecule was normalized to the value of Ppia and then used for statistical comparison among experimental groups in each recovery period. The expression level of the target molecule was presented in a relative ratio to its of Ppia, as an arbitrary unit. The body weight of each animal was recorded on the first and last day of the treatment and before the sacrifice. The testis weight of each animal was expressed in a relative value of wet testis weight, normalized to body weight.

Data in figures were presented as means \pm SEs. Statistical comparison among means of experimental groups in each recovery period was evaluated by one-way analysis of variance (ANOVA), followed by Duncan's post-hoc test. If the $p$-value was lower than 0.05 , it was considered significant.

\section{RESULTS}

\section{Changes in body and testis weights and testicular histology}

There was no significant difference in body weight among experimental groups before ND treatment, but the treatment for 12 weeks resulted in significant decrease in body weights in all treatment groups (Fig. 1). The reduction of body weight was more significant in the $10 \mathrm{mg}$ NDtreated group than the $2 \mathrm{mg}$ ND-treated group (Fig. 1). The recovery period of 2 weeks after the withdrawal of ND treatment was not sufficient to influence the body weight (Fig. 1A). However, the body weight of the $2 \mathrm{mg}$ ND-treated group was not significantly different from the control group, even though the body weight of the $10 \mathrm{mg}$ ND-treated group was significantly lower than other groups (Fig. 1B). The change of body weight at 12 weeks of recovery period was similar to the one seen at 6 weeks of recovery period (Fig. 1C). There was no significant difference in relative testis weights among experimental groups in 2- and 12-weeks recovery periods, except for the 6-week recovery period, showing a significantly heavier testis weight in the $10 \mathrm{mg}$ ND-treated group (Fig. 1D).

Histological changes in the testis after the withdrawal of ND treatment at different recovery periods are shown in Fig. 2. At 2 weeks of recovery period, the space between seminiferous tubules 
(a)

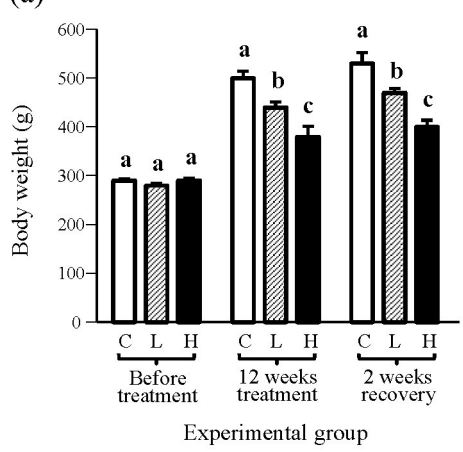

(c)

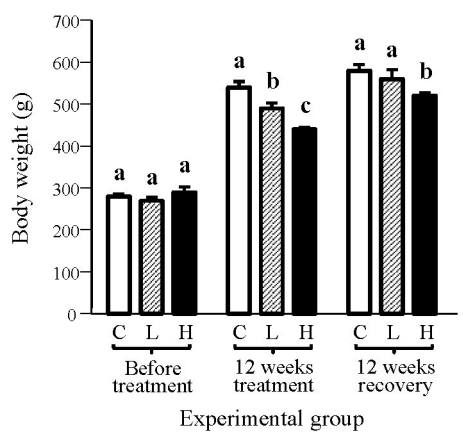

(b)

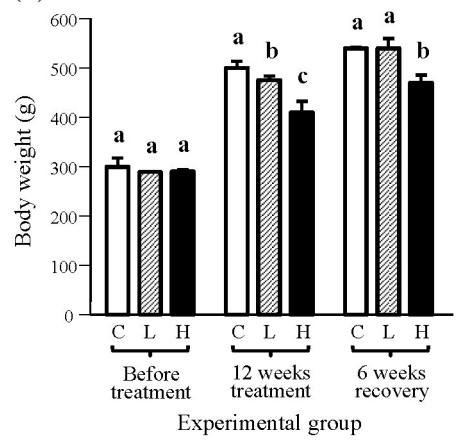

(d)

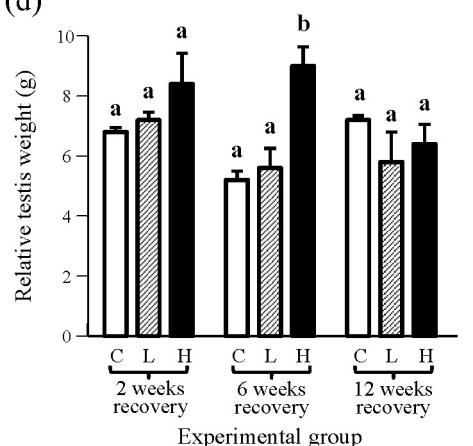

Fig. 1. Changes of body and relative testis weights at different recovery periods after the cease of ND treatment for 12 weeks. At the 2 weeks-recovery period (a), the body weight of low dose (L, 2 mg ND/Kg BW/ week) or high dose $(\mathrm{H}, 10 \mathrm{mg} \mathrm{ND} / \mathrm{Kg} \mathrm{BW} /$ week)-treated group was significantly lower than its of control group (C, peanut oil). However, at the 6 weeks- (b) or 12 weeks-recovery period (c), the body weight of high dosetreated group was lower than those of control and low dose-treated groups. The relative testis weight (d) was only significantly heavier in high dose-treated group at the 6 weeks-recovery period. Different letters indicate significant differences among experimental groups $(p<0.05)$. $\square$, control (peanut oil); $\mathbb{Z}$, a low dose-treated group; n, a high-dose-treated group. ND, nandrolone decanoate; BW, body weight.

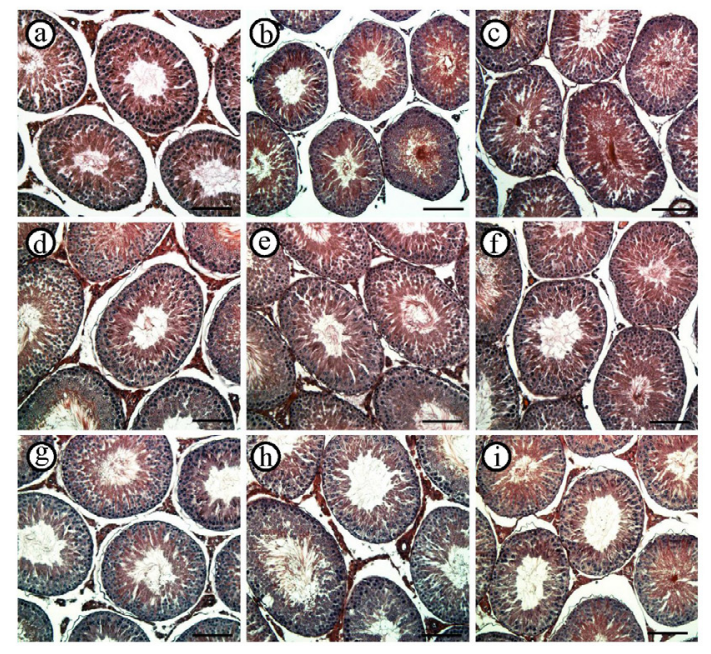

Fig. 2. Representative histological photographs of the testes at different recovery periods after 12 weeks-ND treatment. At 2 weeks (a)_(C), 6 weeks (d)-(1)), and 12 weeks ((9)-(i)-recovery periods, the interstitial compartment in the testis of control group (@), (d), and (9), respectively) was rich with Leydig cells. The testicular interstitium of low dose (2 mg ND/Kg BW/week)-treated group became filled with Leydig cells as the recovery period was longer from 2 weeks (b)), 6 weeks (@), to 12 weeks ((D)). The testis of high dose (10 mg $\mathrm{ND} / \mathrm{Kg} \mathrm{BW/week)-treated} \mathrm{group} \mathrm{at} 2$ weeks (C), 6 weeks (†), or 12 weeks (i))-recovery period was gradually filled with interstitial components. Bars $=50 \mu \mathrm{m}$. ND, nandrolone decanoate; BW, body weight. 
in the testis of the control group was found to be compactly filled with the interstitial constituent, including Leydig cell, while visible interstitial component in very tiny size was sporadically found in the testis of $2 \mathrm{mg}$ or $10 \mathrm{mg}$ of ND-treated group (Fig. 2, top row). Compared with the testis of the control group for the 6-weeks recovery period, the interstitial compartment of the $2 \mathrm{mg} \mathrm{ND}$ treated group became filled with cellular components, even though a few dispersed interstitial elements were observed in the testis of $10 \mathrm{mg}$ ND-treated group (Fig. 2, middle row). For the 12week recovery period, the testicular interstitium of the $2 \mathrm{mg}$ ND-treated group was comparable with the control group, and cellular components between seminiferous tubules of the $10 \mathrm{mg}$ NDtreated group were more cumulated than those in the 6-week recovery period but still noticeably less than the control and $2 \mathrm{mg}$ ND-treated groups (Fig. 2, bottom row). Moreover, severe germ cell sloughing within the seminiferous tubules was not notable in the testis of all ND-treated groups in all recovery periods (data not shown).

\section{Expression change of steroidogenic acute regulatory protein after the withdrawal of nandrolone decanoate treatment}

The 2-week recovery period was not sufficient for returning to the normal expression level of Star in the testis of ND-treated groups (Fig. 3A). The expression level of Star in the testis of the $2 \mathrm{mg}$ ND-treated group was significantly lower than that of control, and the level of Star transcript in the testis of $10 \mathrm{mg} \mathrm{ND}$-treated group was significantly lower than that of the $2 \mathrm{mg}$ ND-treated group (Fig. 3A). However, for the 6-weeks recovery period, the transcript level of Star in the testis of the $2 \mathrm{mg}$ ND-treated group was comparable with that of the control, although the abundance of
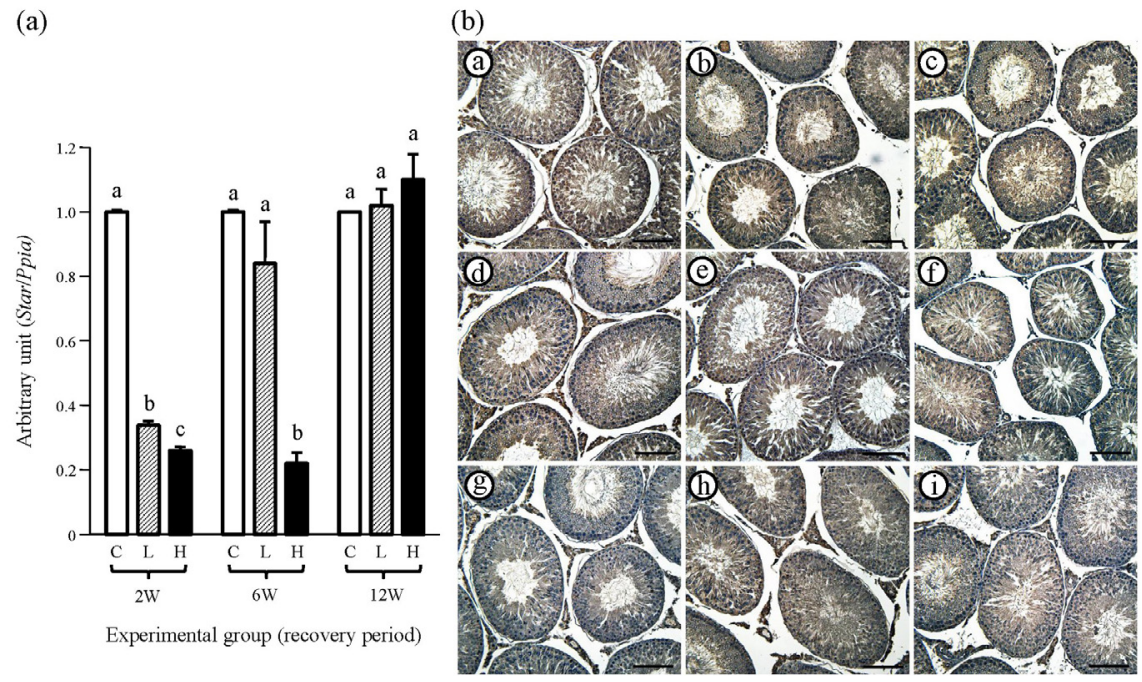

Fig. 3. Effect of a withdrawal of ND treatment on expression of testicular steroidogenic acute regulatory protein. (a) Change of expression level of Star after the withdrawal of ND treatment for 12 weeks. After the ND treatment for 12 weeks at a low dose (L, $2 \mathrm{mg} \mathrm{ND} / \mathrm{Kg} \mathrm{BW} /$ week) or high-dose (H, $10 \mathrm{mg} \mathrm{ND} / \mathrm{Kg} \mathrm{BW} /$ week), the treatment was ceased, and the animals were allowed to have a recovery period for 2 weeks $(2 W), 6$ weeks $(6 W)$, or 12 weeks $(12 W)$. Different letters indicate significant differences among experimental groups $(p<0.05)$. (b) Representative immunohistochemical pictures of STAR in the testis. The strong immuno-staining of STAR was found in the Leydig cells of control (a) testis, but weakly positive of low dose (b)- and high dose (C)-treated groups with 2 weeks-recovery period. With 6 weeks-recovery period, the testes of control (d)) and low dose (e)-treated groups contained the Leydig cells positively stained with STAR, while weak immuno-reactivity of STAR in the Leydig cell was observed with high dose (†)-treatment. The interstitial compartment of control (9) and low dose (ㅁ)- and high dose (i) -treated groups with 12 weeks-recovery period was strongly immunostained for STAR. Bars $=50 \mu \mathrm{m}$. Different letters indicate significant differences among experimental groups

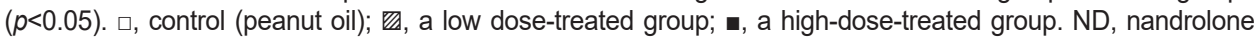
decanoate; BW, body weight. 
Star transcript in the testis of the $10 \mathrm{mg}$ ND-treated group was still significantly less than in other experimental groups (Fig. 3A). The expression levels of testicular Star of $2 \mathrm{mg}$ and $10 \mathrm{mg}$ NDtreated groups were returned to that of the control (Fig. 3A).

The observation from STAR immunohistochemistry in the testis was similar to the findings from real-time PCR analysis (Fig. 3B and Table 2). Strong immuno-localization of STAR was observed in the Leydig cells of the control group in all recovery periods (Fig. 3B and Table 2). No immuno-reactivity of STAR was found within the seminiferous tubules of all experimental groups (Fig. 3B and Table 2). At the 2-weeks recovery period, weakly positive immuno-staining of STAR was detected with the testicular interstitial compartment of $2 \mathrm{mg}$ and $10 \mathrm{mg}$ NDtreated groups (Fig. 3B and Table 2). The interstitial components of the $2 \mathrm{mg}$ ND-treated group at 6-weeks recovery period showed clear immuno-staining of STAR, and weak immuno-reactivity of STAR was also found in the testis of $10 \mathrm{mg}$ ND-treated group (Fig. 3B and Table 2). The immunolocalization of STAR in the Leydig cell was detected in the testis of $2 \mathrm{mg}$ and $10 \mathrm{mg}$ NDtreated groups at the 12-weeks recovery period (Fig. 3B and Table 2). No immuno-reactivity of STAR was detected in negative control (data not shown).

\section{Expression change of cytochrome P450 side-chain cleavage after the withdrawal of nandrolone decanoate treatment}

The expression level of testicular Cyp 11a of the $2 \mathrm{mg}$ ND-treated group at the 2-weeks recovery period was significantly lower than that of the control group, and the Cyp11a transcript level of the $10 \mathrm{mg}$ ND-treated group was even lower than that of the $2 \mathrm{mg}$ ND-treated group (Fig. 4A). However, at 6-weeks recovery period, a significantly higher level of Cyp11a transcript than that of the control group was detected in the testis of the $2 \mathrm{mg}$ ND-treated group, even though the amount of Cyp11a mRNA of $10 \mathrm{mg}$ ND-treated group was significantly lower than those of the control and $2 \mathrm{mg}$ ND-treated groups (Fig. 4A). Even at 12-weeks recovery period, the expression level of Cyp11a of the $2 \mathrm{mg}$ ND-treated group was significantly lower than that of the control group but significantly higher than that of the $10 \mathrm{mg} \mathrm{ND}$-treated group (Fig. 4A).

As expected, positive immuno-staining of CYP11A1 was restricted in the Leydig cell, and the interstitial compartment of all control groups showed strong reactivity of CYP11A1 (Fig. 4B and Table 2). No immuno-reaction of CYP11A1 in the testis of $2 \mathrm{mg}$ and $10 \mathrm{mg}$ ND-treated groups was observed at 2-weeks recovery period (Fig. 4B and Table 2). At 6-weeks recovery period, control and $2 \mathrm{mg}$ ND-treated groups showed strong immunolocalization of CYP11A1 in the Leydig

Table 2. Results of immunohistochemical analysis

\begin{tabular}{|c|c|c|c|c|c|c|c|c|c|c|c|c|c|c|c|c|c|c|c|c|c|c|c|c|c|c|c|}
\hline \multirow{3}{*}{ Molecule } & \multicolumn{9}{|c|}{$2 w$} & \multicolumn{9}{|c|}{$6 w$} & \multicolumn{9}{|c|}{$12 w$} \\
\hline & \multicolumn{3}{|c|}{ Leydig cell } & \multicolumn{3}{|c|}{ Sertoli cell } & \multicolumn{3}{|c|}{ Germ cell } & \multicolumn{3}{|c|}{ Leydig cell } & \multicolumn{3}{|c|}{ Sertoli cell } & \multicolumn{3}{|c|}{ Germ cell } & \multicolumn{3}{|c|}{ Leydig cell } & \multicolumn{3}{|c|}{ Sertoli cell } & \multicolumn{3}{|c|}{ Germ cell } \\
\hline & C & $\mathbf{L}$ & $\mathrm{H}$ & C & $\mathbf{L}$ & $\mathrm{H}$ & C & $\mathbf{L}$ & H & C & $\mathbf{L}$ & $\mathrm{H}$ & C & $\mathbf{L}$ & H & C & L & H & C & L & H & C & L & $\mathrm{H}$ & C & L & $\mathrm{H}$ \\
\hline CYP11A1 & + & - & - & - & - & - & - & - & - & + & + & - & - & - & - & - & - & - & + & + & + & - & - & - & - & - & - \\
\hline CYP17 & + & $+\left(-^{1)}\right.$ & - & - & - & - & - & - & - & + & + & - & - & - & - & - & - & - & + & + & + & - & - & - & - & - & - \\
\hline CYP19 & + & - & - & $+/-$ & $+/-$ & $+/-$ & $+-^{2)}$ & $\left.+/^{2}\right)$ & $+/-^{2)}$ & + & + & $+/-$ & $+/-$ & $+/-$ & $+/-$ & $+\left.\right|^{-2)}$ & $+/^{2)}$ & $+/^{2)}$ & + & + & + & $+/-$ & $+/-$ & $+/-$ & $+/-^{2)}$ & $+/^{2)}$ & $+/^{2)}$ \\
\hline
\end{tabular}

${ }^{1)}$ not all cells positive.

${ }^{2)}$ specific types of germ cells are positive.

w, weeks (recovery period); C, control (peanut oil); L, 2 mg ND/Kg body weight/week-treated; H, $10 \mathrm{mg} \mathrm{ND/Kg} \mathrm{body} \mathrm{weight/week-treated;} \mathrm{+:} \mathrm{positive;} \mathrm{+/-:} \mathrm{weakly} \mathrm{positive;} \mathrm{-,} \mathrm{negative;}$ STAR, steroidogenic acute regulatory protein; CYP11A1, cytochrome P450 side chain cleavage; CYP17, cytochrome P450 17a-hydroxylase; HSD3B1, 33-hydroxysteroid dehydrogenase type 1; HSD17B3, 17ß-hydroxysteroid dehydrogenase 3; CYP19, cytochrome P450 aromatase. 
(a)

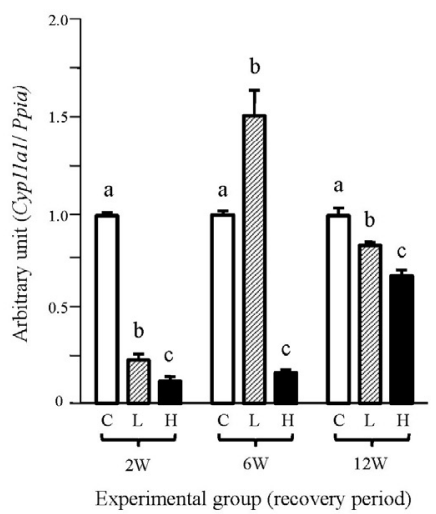

(b)

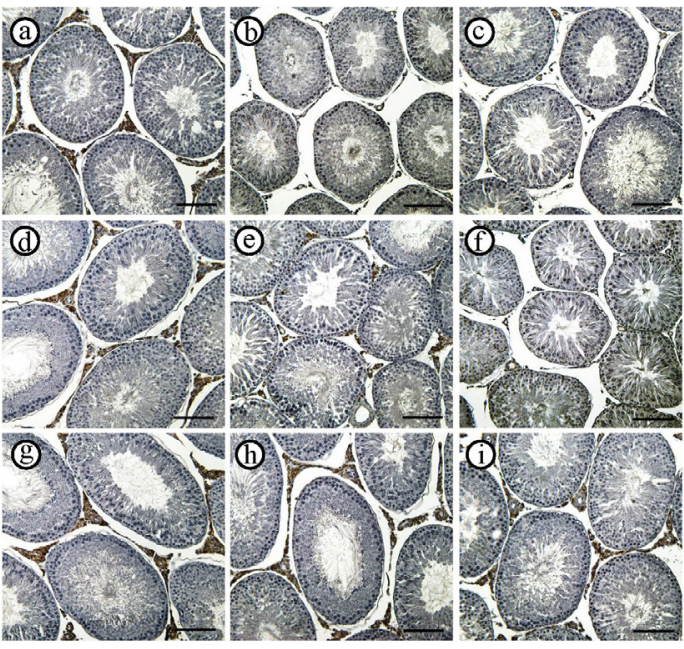

Fig. 4. Effect of a withdrawal of ND treatment on expression of testicular cytochrome P450 side chain cleavage. (a) Change of expression level of Cyp11a1 after the withdrawal of ND treatment for 12 weeks. After the ND treatment for 12 weeks at a low dose (L, $2 \mathrm{mg} \mathrm{ND} / \mathrm{Kg} \mathrm{BW/week)}$ or high-dose $(\mathrm{H}, 10 \mathrm{mg} \mathrm{ND} / \mathrm{Kg} \mathrm{BW} /$ week), the treatment was ceased, and the animals were allowed to have a recovery period for 2 weeks (2W), 6 weeks $(6 \mathrm{~W})$, or 12 weeks $(12 \mathrm{~W})$. Different letters indicate significant differences among experimental groups ( $p$ $<0.05$ ). (b) Representative immunohistochemical pictures of CYP11A1 in the testis. The strong immuno-staining of CYP11A1 was found in the Leydig cells of control (@) testis, but not of low dose (b)-and high dose (C)-treated groups with 2 weeks-recovery period. With 6 weeks-recovery period, the testes of control (d) and low dose (e)-treated groups contained the Leydig cells positively stained with CYP11A1, while no immuno-reactivity of CYP11A1 in the Leydig cell was still observed with high dose (†)-treatment. The interstitial compartment of control (9) and low dose (B)- and high dose (i)-treated groups with 12 weeks-recovery period was strongly immuno-stained for CYP11A1. Bars $=50 \mu \mathrm{m}$. Different letters indicate significant differences among experimental groups $(p<0.05)$. $\square$, control (peanut oil); , a low dose-treated group; $\mathbf{\square}$, a high-dose-treated group. ND, nandrolone decanoate; BW, body weight.

cell, while visible immuno-reactivity of CYP11A1 in the testis of $10 \mathrm{mg}$ ND-treated group was not detected (Fig. 4B and Table 2). However, all experimental groups at 12 -weeks recovery period exhibited positive immuno-staining of CYP11A1 in the Leydig cell (Fig. 4B and Table 2). No immuno-reactivity of CYP11A1 was detected in negative control (data not shown).

\section{Expression change of cytochrome P450 17a-hydroxylase after the withdrawal of nandrolone decanoate treatment}

The changes of testicular Cyp17 expression at different recovery periods after the stop of ND treatment are shown in Fig. 5A. The expression level of $C_{y p} 17$ of the $2 \mathrm{mg}$ ND-treated group for the 2-weeks recovery period was significantly lower than that of the control group but higher than that of the $10 \mathrm{mg}$ ND-treated group (Fig. 5A). A surge in the expression level of Cyp17 was observed in the $2 \mathrm{mg}$ ND-treated group at the 6-weeks recovery period, while Cyp17 mRNA abundance of $10 \mathrm{mg}$ ND-treated group was significantly lower than control and $2 \mathrm{mg}$ ND-treated groups (Fig. 5A). At the 12-weeks recovery period, the Cyp17 transcript level of the control group was significantly higher than two ND-treated groups, which were statistically insignificant (Fig. 5A).

The immunolocalization of CYP17 was limited in the Leydig cell, but not in other testicular cell types (Fig. 5B). At 2-weeks recovery period, strong immuno-staining of CYP17 was detected in the interstitial compartment of the control group (Fig. 5B and Table 2). However, a weak immuno-reactivity of CYP19 in some interstitial cells was observed in the $2 \mathrm{mg}$ ND-treated group, while there was no specific reactivity of CYP19 in the $10 \mathrm{mg}$ ND-treated group (Fig. 5B and Table 2). Strong immuno-staining of CYP19 in the Leydig cell was clearly noticed in the control 
(a)

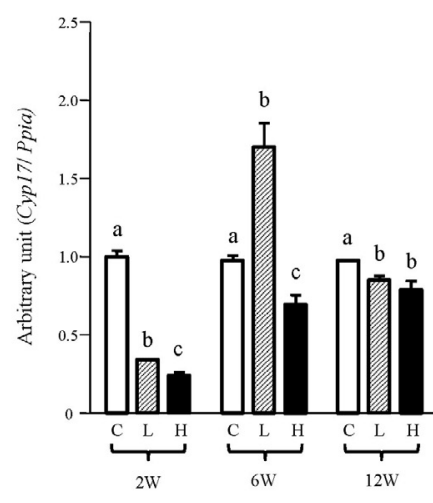

Experimental group (recovery period) (b)

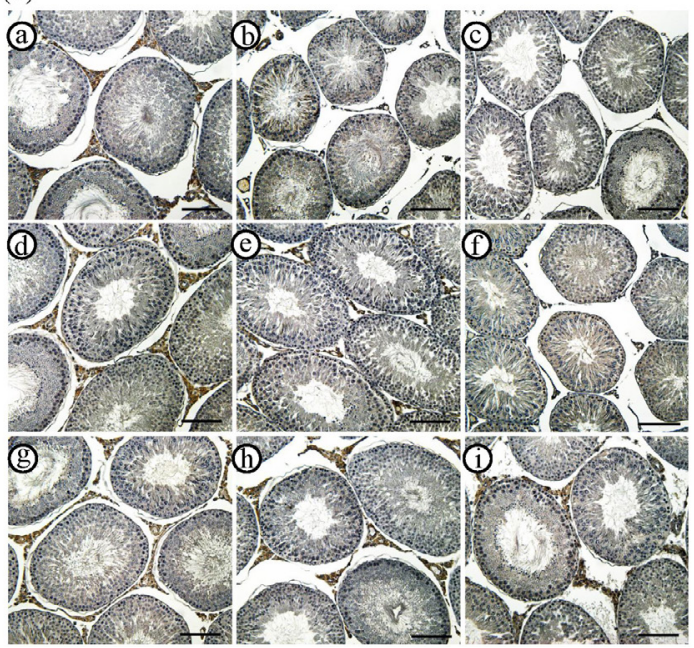

Fig. 5. Effect of a withdrawal of ND treatment on expression of testicular cytochrome P450 17a-hydroxylase. (a) Change of expression level of Cyp17a after the withdrawal of ND treatment for 12 weeks. After the ND treatment for 12 weeks at a low dose (L, $2 \mathrm{mg} \mathrm{ND} / \mathrm{Kg} \mathrm{BW} /$ week) or high-dose (H, $10 \mathrm{mg} \mathrm{ND} / \mathrm{Kg}$ BW/week), the treatment was ceased, and the animals were allowed to have a recovery period for 2 weeks ( $2 \mathrm{~W})$, 6 weeks (6W), or 12 weeks (12W). Different letters indicate significant differences among experimental groups ( $p$ $<0.05$ ). (b) Representative immunohistochemical pictures of CYP17A in the testis. The strong immuno-staining of CYP17A was found in the Leydig cells of control (a) testis with 2 weeks-recovery period. The low dose (b)-treated testis showed weakly positive of CYP17A in the Leydig cell, but not in high dose (C)-treated testis with 2 weeks-recovery period. With 6 weeks-recovery period, the testes of control (@) and low dose (@)-treated groups contained the Leydig cells positively stained with CYP17A, while no immuno-reactivity of CYP17A in the Leydig cell was observed with high dose (๑)-treatment. The interstitial compartment of control (9) and low dose (ㄱ)- and high dose (i)-treated groups with 12 weeks-recovery period was strongly immuno-stained for CYP17A. Bars $=50 \mu \mathrm{m}$. Different letters indicate significant differences among experimental groups $(p<0.05)$. $\square$, control (peanut oil); $\mathbb{Z}$, a low dose-treated group; $\mathbf{n}$, a high-dose-treated group. ND, nandrolone decanoate; BW, body weight.

and $2 \mathrm{mg}$ ND-treated groups at the 6-weeks recovery period (Fig. 5B and Table 2). The positive immunolocalization of CYP17 in the testicular interstitial compartment of the $10 \mathrm{mg}$ ND-treated group was visible at the 12-weeks recovery period, with the control and $2 \mathrm{mg} \mathrm{ND}$-treated groups also having strong CYP17 immuno-stained Leydig cells in the testis (Fig. 5B and Table 2). No immuno-reactivity of CYP17 was detected in negative control (data not shown).

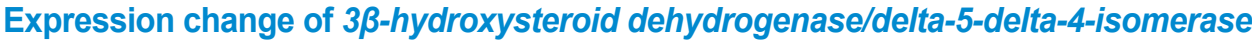
type I after the withdrawal of nandrolone decanoate treatment

The transcript level of $H s d 3 b 1$ of the control group at the 2-weeks recovery period was significantly higher than in the two ND-treated groups, and there was no significant difference in the expression level of $H s d 3 b 1$ between $2 \mathrm{mg}$ and $10 \mathrm{mg}$ ND-treated groups (Fig. 6A). A similar finding among experimental groups was observed at the 6-weeks recovery period (Fig. 6A). The expression level of $H s d 3 b 1$ of the $2 \mathrm{mg}$ ND-treated group at the 12-weeks recovery period was not significantly different from that of the control group, although the $H s d 3 b 1$ transcript level of the $10 \mathrm{mg}$ NDtreated group was lower than those of the control and $2 \mathrm{mg}$ ND-treated groups (Fig. 6A).

The intense immuno-reactivity of HSD3B1 in the testis of the control group at all recovery periods was restricted in the Leydig cell (Fig. 6 and Table 2). The weak immuno-stained interstitial components of HSD3B1 were very occasionally observed in the testis of $2 \mathrm{mg}$ or $10 \mathrm{mg}$ NDtreated group at the 2-weeks recovery period (Fig. 6 and Table 2). At the 6-weeks recovery period, strong immuno-reactivity of HSD3B1 in the Leydig cell was visible in the testis of $2 \mathrm{mg}$ or $10 \mathrm{mg}$ 
(a)

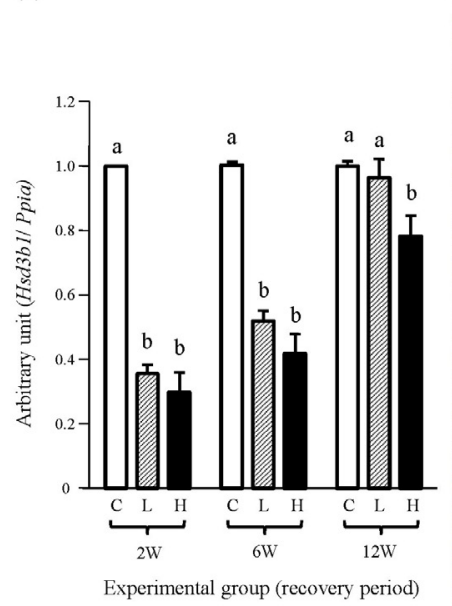

(b)

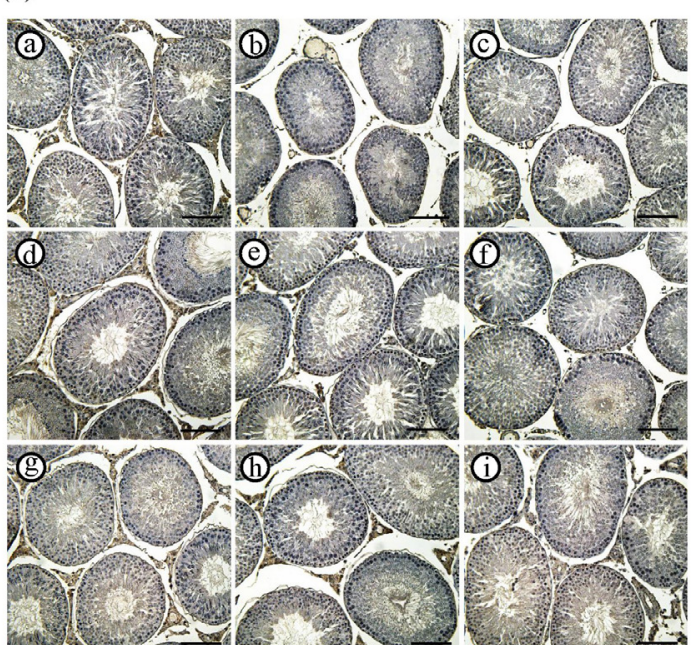

Fig. 6. Effect of a withdrawal of ND treatment on expression of testicular $3 \beta$-hydroxysteroid dehydrogenase type 1. (a) Change of expression level of Hsd3b1 after the withdrawal of ND treatment for 12 weeks. After the ND treatment for 12 weeks at a low dose (L, $2 \mathrm{mg} \mathrm{ND/Kg} \mathrm{BW/week)} \mathrm{or} \mathrm{high-dose}(\mathrm{H}, 10$

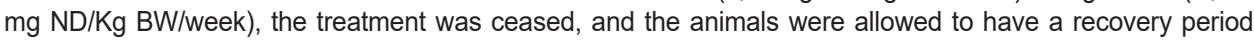
for 2 weeks $(2 \mathrm{~W}), 6$ weeks $(6 \mathrm{~W})$, or 12 weeks $(12 \mathrm{~W})$. Different letters indicate significant differences among experimental groups $(p<0.05)$. (b) Representative immunohistochemical pictures of HSD3B1 in the testis. The strong immuno-staining of HSD3B1 was found in the Leydig cells of control (a) testis with 2 weeks-recovery period. The low dose (b)- treated testis showed weakly positive of HSD3B1 in the Leydig cell, but not all Leydig cell in high dose (C)-treated testis was immuno-positive with 2 weeks-recovery period. With 6 weeks-recovery period, the testes of control (@) and low dose (e)- and high dose (†)-treated groups contained the Leydig cells positively stained with HSD3B1. The interstitial compartment of control (9)) and low dose ((D))- and high dose (i)-treated groups with 12 weeks-recovery period was strongly immuno-stained for HSD3B1. Bars $=50 \mu \mathrm{m}$. Different letters indicate significant differences among experimental groups $(p<0.05)$. $\square$, control (peanut oil); $\mathbb{Z}$, a low dose-treated group; $\mathbf{n}$, a high-dose-treated group. ND, nandrolone decanoate; BW, body weight.

ND-treated group (Fig. 6 and Table 2). Additionally, more HSD3B1-stained cells were detected within the interstitial compartment of the $2 \mathrm{mg}$ or $10 \mathrm{mg}$ ND-treated group (Fig. 6 and Table 2). No immuno-reactivity of HSD3B1 was detected in negative control (data not shown).

\section{Expression change of $17 \beta$-hydroxysteroid dehydrogenase 3 after the withdrawal of nandrolone decanoate treatment}

The transcript level of testicular $H s d 17 b 3$ of $2 \mathrm{mg}$ or $10 \mathrm{mg}$ ND-treated group was significantly lower than that of the control group at the 2-weeks recovery period, and no significant difference in Hsd17b3 mRNA level between the two ND-treated groups was observed (Fig. 7A). At the 6-weeks recovery period, the abundance of $H s d 17 b 3 \mathrm{mRNA}$ of the control group was still significantly higher than in the two ND-treated groups, which were not different (Fig. 7A). However, the expression level of testicular $H_{s} d 17 b 3$ of the $2 \mathrm{mg}$ ND-treated group was not significantly different from that of the control group, even though the Hsd17b3 transcript level of the $10 \mathrm{mg}$ ND-treated group was lower than in other groups (Fig. 7A).

The immuno-reactivity of HSD17B3 in the testis of the control group was localized in the Leydig cell and specific types of germ cells, but not in the Sertoli cell (Fig. 7B and Table 2). Additionally, the immuno-intensity of HSD17B3 in specific germ cells was not visibly changed by the ND treatment (Fig. 7B and Table 2). At the 2-weeks recovery period, there was no immunoreaction of HSD17B3 in the Leydig cell of the two ND-treated groups (Fig. 7B and Table 2). The intense immunolocalization of HSD17B3 in the Leydig cell was observed in control and $2 \mathrm{mg}$ ND-treated groups at the 6-weeks recovery period. However, immuno-intensity of 
(a)

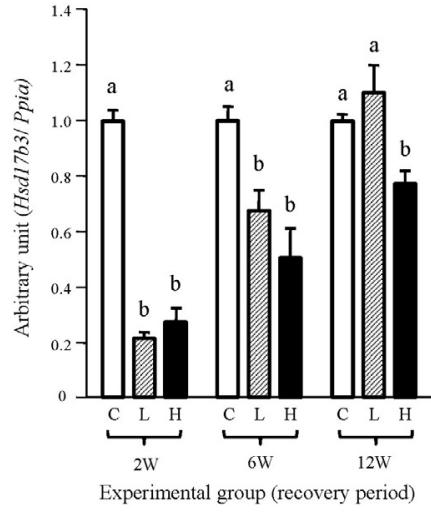

(b)

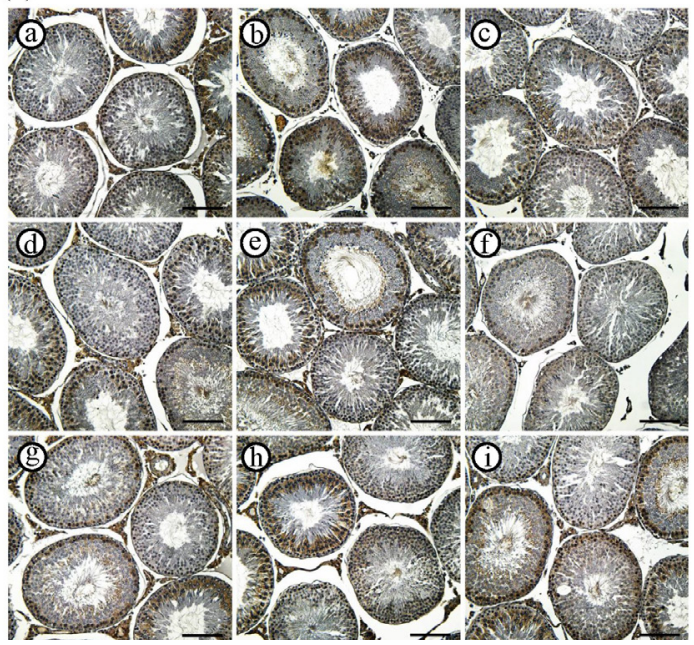

Fig. 7. Effect of a withdrawal of ND treatment on expression of testicular hydroxysteroid $17 \beta$ dehydrogenase 3. (a) Change of expression level of Hsd17b3 after the withdrawal of ND treatment for 12 weeks. After the ND treatment for 12 weeks at a low dose (L, $2 \mathrm{mg} \mathrm{ND/Kg} \mathrm{BW/week)} \mathrm{or} \mathrm{high-dose}(\mathrm{H}, 10$ $\mathrm{mg} \mathrm{ND} / \mathrm{Kg} \mathrm{BW} /$ week), the treatment was ceased, and the animals were allowed to have a recovery period for 2 weeks $(2 \mathrm{~W}), 6$ weeks $(6 \mathrm{~W})$, or 12 weeks $(12 \mathrm{~W})$. Different letters indicate significant differences among experimental groups $(p<0.05)$. (b) Representative immunohistochemical pictures of HSD17B3 in the testis. The strong immuno-staining of HSD17B3 was found in the Leydig cells of control (a) testis with 2 weeksrecovery period. No immuno-reactivity of HSD17B3 was detected in the testis of low dose (b)- and high dose (C)-treated testis. With 6 weeks-recovery period, the testes of control (@) and low dose (@)- and high dose (†)-treated groups contained the Leydig cells positively stained with HSD17B3. The interstitial compartment of control (9) and low dose ((D)- and high dose (i)-treated groups with 12 weeks-recovery period was strongly immuno-stained for HSD17B3. Specific germ cell types were always immuno-positive for HSD17B3, regardless dose of ND treatment and recovery period. Bars $=50 \mu \mathrm{m}$. Different letters indicate significant differences among

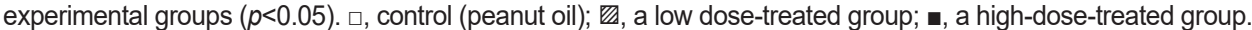
$\mathrm{ND}$, nandrolone decanoate; BW, body weight.

HSD17B3 in the Leydig cell of $10 \mathrm{mg}$ ND-treated group was weak (Fig. 7B and Table 2). Positive immunoreactivity of HSD17B3 in the Leydig cell at the 12-weeks recovery period was visible in the testes of all experimental groups (Fig. 7B and Table 2). No immuno-reactivity of HSD17B3 was detected in negative control (data not shown).

\section{Expression change of cytochrome $\mathbf{P 4 5 0}$ aromatase after the withdrawal of nandrolone decanoate treatment}

The changes of testicular Cyp19 transcript level at different recovery periods after 12 weeks of ND treatment are shown in Fig. 8A. The transcript levels of $C_{y p} 19$ in the testes among all experimental groups at the 2-weeks recovery period were not significantly different (Fig. 8A). Additionally, there was no significant difference in testicular Cyp19 transcript level among all experimental groups at both 6- and 12-weeks recovery periods (Fig. 8A).

Immunohistochemical localization of CYP19 in the testis was found in the Leydig, Sertoli, and certain types of germ cells in the control group (Fig. 8B and Table 2). At the 2-weeks recovery period, there was no visible immunoreactivity within the interstitial compartment of the $2 \mathrm{mg}$ or $10 \mathrm{mg}$ ND-treated group, even though the Sertoli and ger cells were weakly immuno-positive for CYP19 in all experimental groups (Fig. 8B and Table 2). Relatively intensive immuno-staining of CYP19 in the Leydig cell of the $2 \mathrm{mg}$ ND-treated group was found at the 6-weeks recovery period (Fig. 8B and Table 2). Also, weak immunolocalization of CYP19 in the Leydig cell at the 6 weeks-recovery period was detected in the $10 \mathrm{mg}$ ND-treated group (Fig. 8B and Table 2). As at 
(a)

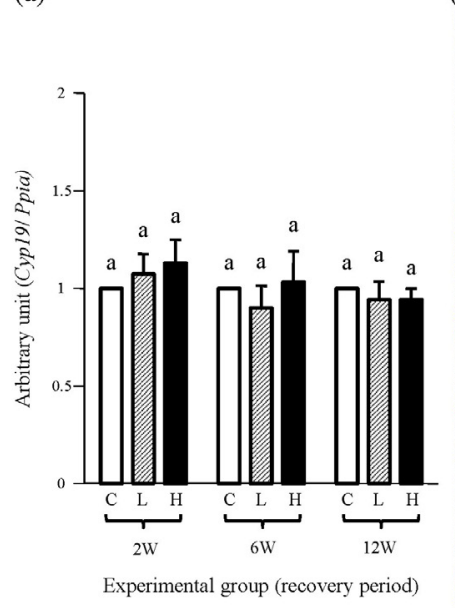

(b)

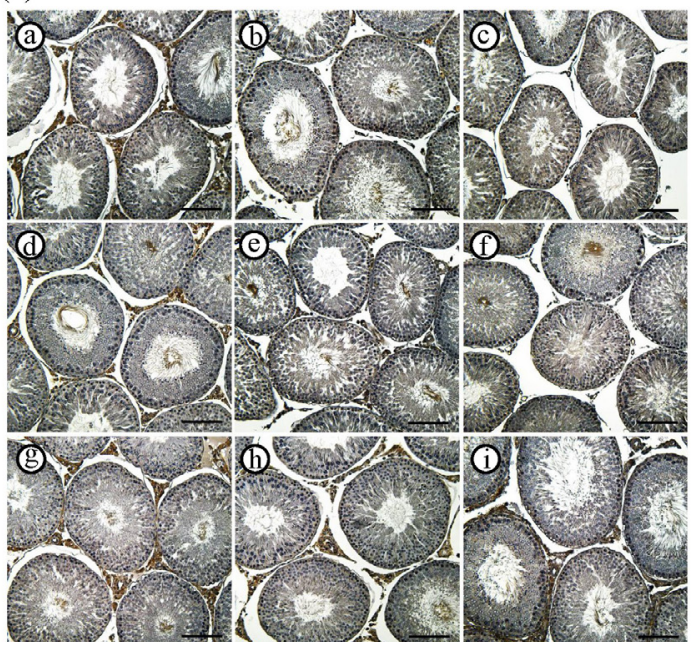

Fig. 8. Effect of a withdrawal of ND treatment on expression of testicular cytochrome P450 aromatase. (a) Change of expression level of Cyp19 after the withdrawal of ND treatment for 12 weeks. After the ND treatment for 12 weeks at a low dose (L, $2 \mathrm{mg} \mathrm{ND/Kg} \mathrm{BW/week)} \mathrm{or} \mathrm{high-dose} \mathrm{(} \mathrm{H}, 10 \mathrm{mg} \mathrm{ND} / \mathrm{Kg} \mathrm{BW} /$ week), the treatment was ceased, and the animals were allowed to have a recovery period for 2 weeks $(2 \mathrm{~W}), 6$ weeks $(6 \mathrm{~W})$, or 12 weeks $(12 W)$. Different letters indicate significant differences among experimental groups $(p<0.05)$. (b) Representative immunohistochemical pictures of CYP19 in the testis. For 2 weeks-recovery period, the strong immuno-staining of CYP19 was found in the Leydig cells of control (a) testis, but not of low dose (b)- and high dose (C)-treated testis. With 6 weeks-recovery period, the testes of control (@) and low dose (@)- and high dose $(\oplus)$-treated groups contained the Leydig cells positively stained with CYP19. The interstitial compartment of control (9) and low dose ((口)- and high dose (i) -treated groups with 12 weeks-recovery period was strongly immuno-stained for CYP19. The Sertoli cells and specific types of germ cells were always weakly immunopositive for CYP19, regardless dose of ND treatment and recovery period. Bars $=50 \mu \mathrm{m}$. Different letters indicate significant differences among experimental groups $(p<0.05)$. $\square$, control (peanut oil); $\mathbb{Z}$, a low dose-

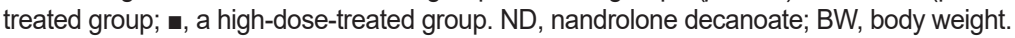

the 2-weeks recovery period, the Sertoli and certain germ cells at the 6-weeks recovery period were weakly positive for CYP19 (Fig. 8B and Table 2). At the 12-weeks recovery period, the Leydig cells of all experimental groups were immuno-stained for CYP19, and the Sertoli and specific germ cells were weakly positive for CYP19 (Fig. 8B and Table 2). No immuno-reactivity of CYP19 was detected in negative control (data not shown).

\section{DISCUSSION}

Our previous research has shown that exposure to ND with even low doses for a long period results in histological disruption and abnormal expression of steroidogenic enzymes in the testis [12]. Therefore, the effect of the withdrawal of ND administration on the testis has been examined at histological and transcript expression levels. The findings from the current research are summarized as follows: 1) the changes of body and testis weights induced by the ND treatment are returned to normal levels, 2) the occurrence of germ cell sloughing within seminiferous tubules is visibly reduced, 3) the depletion of interstitial composites by prolonged ND exposure is alleviated as the recovery period progresses, 4) expression levels of testicular steroidogenic enzymes at longer recovery periods tend to return to normal levels, even though there are some variations in enzymatic molecules, and 5) the degree of immunohistochemical intensity detected within the interstitial compartment is strongly associated with the recurrence of cellular components, most likely Leydig cell, as the recovery period is getting longer.

The long-term usage of ND in a normal state results in decreased body and testicular weights 
$[12,15,21]$, even though the administration of ND for clinical treatment mostly induces body weight gain [4]. In the present research, a decrease in body weight after ND treatment for 12 weeks is in line with our previous study's findings [12]. As the recovery period progresses, the body weight of the $2 \mathrm{mg}$ ND-treated group becomes comparable with that of the control group. However, the 12 -weeks recovery period is not enough for the $10 \mathrm{mg}$ ND-treated group to completely regain body weight to the level of the control group, even though the difference in body weight between the $10 \mathrm{mg}$ ND-treated group and other groups diminishes at a longer recovery period. It is considered that a longer recovery period than the ND-exposed one is necessary to make up for normal body weight. Unlike the change of body weight after the withdrawal of the ND treatment, the testis weight of the ND-treated group quickly returns to the control level at even the 2-weeks recovery period. Nonetheless, a transient surge of testis weight of $10 \mathrm{mg}$ ND-treated group at the 6-weeks recovery period is not clearly explainable at this point. This phenomenon might be acceptable if the rate of testis weight gain in $10 \mathrm{mg} \mathrm{ND}$-treated group between the 2-weeks and 6-weeks recovery period is faster than the rate in body weight gain.

The histological aberrance in the testis induced by the exposure to ND is frequently detected $[11,12,15,22]$. The germ cell sloughing following the detachment of germ cells from the seminiferous epithelium is often accompanied with ND administration by not only injection $[11,12]$ but also feeding [22]. The loss of germ cells from the seminiferous epithelium is associated with endogenous testosterone level reduction [23]. In fact, the ND treatment results in a drop in serum and testosterone concentration [11,12]. Moreover, the incidence of germ cell sloughing after the cease of ND treatment has not been remarkable. Thus, it is speculated that even the 2-weeks recovery period is sufficient to allow the regeneration of the interstitial Leydig cell population, which produces an adequate amount of testicular testosterone to suppress the germ cell sloughing.

Another evident histological change observed in the ND-treated testis is the depletion of interstitial components, including Leydig cells [11,12]. Such reduction of Leydig cell population is strongly associated with the decrease of serum or testicular testosterone level by the ND treatment $[11,12]$. Direct quantitative comparison of the number of cellular components within testicular interstitium at the final injection of ND and at the 2-weeks recovery period after the withdrawal of ND treatment is impossible at this point. However, light microscopic evaluation of the testis has observed sporadic and clear Leydig cell population within the interstitial compartment of the testis at the 2-weeks recovery period, which was not the case right after the final ND injection (observations not described in the results). Even though the space between seminiferous tubules becomes filled with more interstitial components as the recovery period becomes longer, the testis of $10 \mathrm{mg}$ ND-treated group at the 12-weeks recovery period still has a loose interstitial compartment. Based on these findings, it is supposed that the complete return of abnormal testicular histology caused by the ND exposure requires a longer recovery period than the exposure period. The withdrawal effect of ND on other tissues has been examined from other researches, and the permanent irreversibility of abnormal characteristics induced by the ND treatment has been suggested $[15,16,18-20]$. Thus, the results indicating that a longer recovery period guarantees a complete reverse of testicular histological aberrance derived by the ND treatment are not conclusive. Further and longer period-course research is proposed to determine the effect of withdrawal of the ND treatment on the testicular histology in detail.

The expression and activity of testicular steroidogenic enzymes are suppressed by long-term and/ or high-dose ND treatment [12,21]. Our previous research has demonstrated that the treatment of $10 \mathrm{mg} \mathrm{ND} /$ week for 12 weeks results in significant decreases in transcript and protein levels of testicular steroidogenic enzymes, including STAR, CYP11A1, CYP17, HSD3B1, and CYP19 [12]. The reduction of HSD17B activity has also been detected in the testis of $10 \mathrm{mg} \mathrm{ND} /$ week 
treatment for 8 weeks [21]. As a serial action of these enzymes is required for the synthesis of steroid hormones in the testis, a disruption in expression and/or activity of these enzymes in the testis could alter the production of testicular testosterone. Indeed, the drop in testosterone concentration in serum or testis has been detected with the ND treatment [12,21]. In the present study, the expression level of testicular Cyp19 at the 2-weeks recovery period after the withdrawal of ND treatment has been restored to the control level. However, expression levels of other testicular steroidogenic enzymes of ND-treated groups at the 2-weeks recovery period are still significantly lower than those of the control group.

At the 6-weeks recovery period, expression levels of Star in the $2 \mathrm{mg}$ ND-treated group and Cyp 19 of $2 \mathrm{mg}$ and $10 \mathrm{mg}$ ND-treated groups have been returned to those of the control group. Moreover, expression levels of Cyp11a1 and Cyp17 of the $2 \mathrm{mg}$ ND-treated group are significantly higher than those of the control group. Such transient increases in testicular Cyp11a1 and Cyp17 transcripts in the $2 \mathrm{mg}$ ND-treated group are unexpected. As no similar phenomenon has been observed in other steroidogenic enzymes, such remarkable changes in the transcript levels in the $2 \mathrm{mg}$ ND-treated group seem to be restricted in the expression of Cyp11a1 and Cyp17 but not of other enzymes. Detailed research is suggested to resolve the existence of specific regulatory mechanisms in the expression of Cyp11a1 and Cyp17 in the $2 \mathrm{mg}$ ND-treated group at 6-weeks recovery period.

Providing the 12-weeks recovery period after the ND treatment allows for restoration to the normal transcript level of Hsd3b1 and Hsd17b3 at the $2 \mathrm{mg}$ ND-treated group and Star and Cyp19 in all ND-treated groups. However, expression levels of other molecules in ND-treated groups have not been reached to those in the control group. Such differential expression responsiveness to the same stimulus depending on the molecule is frequent. For example, treatment with the same dose and duration of ND results in differential expression patterns in testicular steroidogenic enzymes at mRNA and/or protein levels [12]. Additionally, a differential expression of androgen and estrogen receptors has been detected in the ampulla of the female reproductive tract at a certain recovery period after the withdrawal of ND treatment [19]. Thus, it is reasonable to consider that different expression patterns of testicular steroidogenic enzymes to the withdrawal of ND treatment could be due to the divergence of expressional regulation, partly depending on the molecule.

Direct measurement of testicular testosterone concentration and quantitative analysis of steroidogenic enzymes at the protein level has not been achieved in this research. Thus, the change of endogenous testosterone synthesis during the recovery period after the withdrawal of the ND treatment could not be provided. However, this issue could be interpreted by observations acquired from immunohistochemical and histological analyses. Except for the immuno-staining within seminiferous tubules, positive immuno-reactivities of all molecules have become stronger and/or more prevalent in the interstitial compartment as the recovery period progresses. This phenomenon is supported by a histological finding that a more compact interstitial compartment is filled with cellular components in the testis at the 12-weeks recovery period, compared to the 2-weeks recovery period. Besides, the transcript and protein levels of certain molecules are usually closely related, as shown in our previous study [12]. Overall, it is supposed that testosterone production in ND-treated testis would gradually increase along with the reappearance of Leydig cells within the interstitial compartment, as the recovery period progresses. Despite such weak points of the current research, this is, to our knowledge, the first report showing a comprehensive analysis of expression changes of testicular steroidogenic enzymes after the ND treatment's withdrawal.

An interesting finding is the immunolocalization of HSD17B3 within seminiferous tubules, along with Leydig cells in the interstitial compartment. It is generally considered that testicular HSD17B3 is only localized in the Leydig cell of the testis [24], and a clear positive immuno- 
reactivity of HSD17B3 in rat Leydig cell has been observed in the current study. However, a strong immunolocalization of HSD17B3 in rat testis has also been detected in certain germ cell types, presumably spermatocytes, of certain spermatogenic stages. However, the specific localization of HSD17B3 in germ cells has not yet been defined. The function of HSD17B3 is responsible for the conversion of androstenedione to testosterone [24]. Thus, the existence of HSD17B3 in specific germ cells could be relevant to the production of testosterone within the seminiferous tubule, which involves local regulation for maintaining the structure and function of cells residing within the germinal epithelium. A detailed molecular examination is required to reveal the existence and function of HSD17B3 in the seminiferous tubule.

The AAS usage does not guarantee complete restoration of spermatogenesis and testosterone production, diminished by AAS [25]. The AAS-induced hypogonadism is not fully reversible after the withdrawal of AAS in some cases [26]. Additionally, although the hypogonadism and azoospermia induced by AAS abuse are reversible after steroid withdrawal, it requires a longer recovery period than expected [6]. Moreover, incomplete recovery of structural aberrance caused by the ND exposure is frequently found in various tissues $[15,16,18]$. Similar outcomes have been observed in the present research, showing that the same recovery duration with the ND-treated period is insufficient for the complete reversal of ND-induced changes at histological and molecular biological levels. Even though nandrolone and/or AAS-like substances are most likely contracted by intramuscular injection, exposure to nandrolone and its derivatives could be accomplished by the consumption of pork, containing non-negligible levels of nandrolone and testosterone metabolites [27,28]. Mendiola et al. [29] have reported a negative relationship between semen quality and a frequent intake of meat products. Thus, these findings suggest that repeated and lasting exposure to nandrolone and/or AAS-like elements, even at a very low dose, could cause permanent obstruction in the testis, eventually affecting sperm production and further fertility. In conclusion, the complete recovery of ND-induced unfavorable outcomes in the testis would not be accomplished simply by the withdrawal of ND administration. Even at this point, it is not clear whether the aberrance caused by the exposure to ND is completely reversible. The time-course analysis for the more extended period is suggested to determine if a complete recovery of testicular damages occurred by ND usage is possible. Besides, the results obtained in this study pave the way for clinical trials and are useful for studies related to the effect of meat on animal's growth and development.

\section{REFERENCES}

1. Bergink EW, Janssen PSL, Turpun EW, van der Vies J. Comparison of the receptor binding properties of nandrolone and testosterone under in vitro and in vivo conditions.J Steroid Biochem. 1985;22:831-6. https://doi.org/10.1016/0022-4731(85)90293-6

2. Schwarzenberger F, Toole GS, Christie HL, Raeside JI. Plasma levels of several androgens and estrogens from birth to puberty in male domestic pigs. Eur J Endocrinol 1993;128:173-7. https://doi.org/10.1530/acta.0.1280173

3. De Wasch K, Le Bizec B, De Brabander H, André F, Impens S. Consequence of boar edible tissue consumption on urinary profiles of nandrolone metabolites. II. Identification and quantification of 19-norsteroids responsible for 19-norandrosterone and 19-noretiocholanolone excretion in human urine. Rapid Commun Mass Spectrom 2001;15:1442-7. https://doi. org/10.1002/rcm.391

4. Busardo FP, Frati P, Sanzo MD, Napoletano S, Pinchi E, Zaami S, et al. The impact of nandrolone decanoate on the central nervous system. Curr Neuropharmacol. 2015;13:122-31. https://doi.org/10.2174/1570159X13666141210225822 
5. Patanè FG, Liberto A, Maria Maglitto AN, Malandrino P, Esposito M, Amico F, et al. Nandrolone decanoate: use, abuse and side effects. Medicina. 2020;56:606. https://doi.org/10.3390/ medicina56110606

6. Boyadjiev NP, Georgieva KN, Massaldjieva RI, Gueorguiev SI. Reversible hypogonadism and azoospermia as a result of anabolic-androgenic steroid use in a bodybuilder with personality disorder. A case report. J Sports Med Phys Fitness. 2000;40:271-4.

7. Smith LB, Walker WH. The regulation of spermatogenesis by androgens. Semin Cell Dev Biol. 2014;30:2-13. https://doi.org/10.1016/j.semcdb.2014.02.012

8. Zirkin BR, Papadopoulos V. Leydig cells: formation, function, and regulation. Biol Reprod. 2018;99:101-11. https://doi.org/10.1093/biolre/ioy059

9. Carreau S, Lambard S, Delalande C, Denis-Galeraud I, Bilinska B, Bourguiba S. Aromatase expression and role of estrogens in male gonad: a review. Reprod Biol Endocrinol. 2003;1:35. https://doi.org/10.1186/1477-7827-1-35

10. Nagata S, Kurosawa M, Mima K, Nambo Y, Fujii Y, Watanabe G, et al. Effects of anabolic steroid (19-nortestosterone) on the secretion of testicular hormones in the stallion. Reprod Fertil 1999;115:373-9. https://doi.org/10.1530/jrf.0.1150373

11. Jannatifar R, Shokri S, Farrokhi A, Nejatbakhsh R. Effect of supraphysiological dose of Nandrolone Decanoate on the testis and testosterone concentration in mature and immature male rats: a time course study. Int J Reprod Biomed. 2015;13:779-86.

12. Min T, Lee KH. Effects of nandrolone decanoate on expression of steroidogenic enzymes in the rat testis. Asian-Australas J Anim Sci. 2018;31:658-71. https://doi.org/10.5713/ ajas.17.0899

13. Koeva YA, Georgieva KN, Atanassova PK, Delchev SD. Effects of submaximal training and anabolic androgenic steroids administration on steroidogenic enzyme activity in rat Leydig cells. Folia Med (Plovdiv). 2003;45:37-40.

14. Barone R, Pitruzzella A, Marino Gammazza A, Rappa F, Salerno M, Barone F, et al. Nandrolone decanoate interferes with testosterone biosynthesis altering blood-testis barrier components.J Cell Mol Med 2017;21:1636-47. https://doi.org/10.1111/jcmm.13092

15. Kahal A, Allem R. Reversible effects of anabolic steroid abuse on cyto-architectures of the heart, kidneys and testis in adult male mice. Biomed Pharmacother. 2018;106:917-22. https:// doi.org/10.1016/j.biopha.2018.07.038

16. Shalaby AM, Bahey NG. Reversal of the hepatic damage induced by the supraphysiological dose of nandrolone decanoate after its withdrawal in the adult male rat. Tissue Cell. 2018;53:44-52. https://doi.org/10.1016/j.tice.2018.05.013

17. Teruel JL, Lasuncion MA, Rivera M, Aguilera A, Ortega H, Tato A, et al. Nandrolone decanoate reduces serum lipoprotein(a) concentrations in hemodialysis patients. Am J Kidney Dis. 1997;29:569-75. https://doi.org/10.1016/S0272-6386(97)90340-1

18. Simão VA, Berloffa Belardin L, Araújo Leite GA, de Almeida Chuffa LG, Camargo ICC. Effects of different doses of nandrolone decanoate on estrous cycle and ovarian tissue of rats after treatment and recovery periods. Int J Exp Pathol. 2015;96:338-49. https://doi.org/10.1111/ iep. 12144

19. Andrade GHB, Simão VA, Souza BR, Chuffa LGA, Camargo ICC. Sex steroid receptors profiling is influenced by nandrolone decanoate in the ampulla of the fallopian tube: post-treatment and post-recovery analyses. Tissue Cell. 2018;50:79-88. https://doi.org/10.1016/ j.tice.2018.01.001

20. Belardin LB, Simão VA, Leite GAA, de Almeida Chuffa LG, Camargo ICC. Dose-dependent effects and reversibility of the injuries caused by nandrolone decanoate in uterine tissue 
and fertility of rats. Birth Defects Res B Dev Reprod Toxicol. 2014;101:168-77. https://doi. org/10.1002/bdrb.21104

21. Ahmed MAE. Amelioration of nandrolone decanoate-induced testicular and sperm toxicity in rats by taurine: effects on steroidogenesis, redox and inflammatory cascades, and intrinsic apoptotic pathway. Toxicol Appl Pharmacol. 2015;282:285-96. https://doi.org/10.1016/j.taap.2014.12.007

22. Lee DM, Min T, Choi I, Cheon YP, Chun T, Park CS, et al. Feeding effect of an anabolic steroid, nandrolone, on the male rat testis. Asian-Australas J Anim Sci. 2010;23:1566-77. https:// doi.org/10.5713/ajas.2010.10278

23. Wong CH, Xia W, Lee NPY, Mruk DD, Lee WM, Cheng CY. Regulation of ectoplasmic specialization dynamics in the seminiferous epithelium by focal adhesion-associated proteins in testosterone-suppressed rat testes. Endocrinology. 2005;146:1192-204. https://doi. org/10.1210/en.2004-1275

24. Knapczyk-Stwora K, Grzesiak M, Slomczynska M. Altered expression of 3ß-HSD, CYP17 and $17 \beta-H S D$ in the foetal porcine gonads in response to anti-androgen flutamide exposure. Reprod Domest Anim. 2014;49:725-33. https://doi.org/10.1111/rda.12356

25. McBride JA, Coward RM. Recovery of spermatogenesis following testosterone replacement therapy or anabolic-androgenic steroid use. Asian J Androl. 2016;18:373-80. https://doi. org/10.4103/1008-682X.173938

26. Vilar Neto JO, da Silva CA, Bruno da Silva CA, Pinto DV, Caminha JSR, de Matos RS, et al. Anabolic androgenic steroid-induced hypogonadism, a reversible condition in male individuals? A systematic review. Andrologia. 2021;53:e14062. https://doi.org/10.1111/and.14062

27. van Ginkel LA, Stephany RW, Zoontjes PW, van Rossum HJ, van Blitterswijk H, Zuijdendorp J. The presence of nortestosterone in edible parts from non-castrated male pigs. Tijdschr Diergeneeskd 1989;114:311-4.

28. Scarth J, Akre C, van Ginkel L, Le Bizec B, De Brabander H, Korth W, et al. Presence and metabolism of endogenous androgenic-anabolic steroid hormones in meat-producing animals: a review. Food Addit Contam Part A 2009;26:640-71. https://doi. org/10.1080/02652030802627160

29. Mendiola J, Torres-Cantero AM, Moreno-Grau JM, Ten J, Roca M, Moreno-Grau S, et al. Food intake and its relationship with semen quality: a case-control study. Fertil Steril 2009;91:812-8. https://doi.org/10.1016/j.fertnstert.2008.01.020 